\title{
Assessment of Recycled Aggregate Concrete
}

\author{
Ismail Abdul Rahman \\ Faculty of Civil and Environmental Engineering \\ Faculty of Mechanical and Manufacturing Engineering, Universiti Tun Hussein Onn Malaysia \\ 86400 Parit Raja, Johore, Malaysia \\ E-mail: ismailar@uthm.edu.my \\ Hasrudin Hamdam \\ Faculty of Civil and Environmental Engineering \\ Faculty of Mechanical and Manufacturing Engineering, Universiti Tun Hussein Onn Malaysia \\ 86400 Parit Raja, Johore, Malaysia \\ Ahmad Mujahid Ahmad Zaidi (Corresponding author) \\ Faculty of Mechanical and Manufacturing Engineering, Universiti Tun Hussein Onn Malaysia \\ 86400 Parit Raja, Johore, Malaysia \\ E-mail: mujahid@uthm.edu.my
}

\begin{abstract}
Used of recycled aggregate (RA) in concrete can be described in environmental protection and economical terms. The application of recycled aggregate to use in construction activities have been practice by developed European countries and also of some Asian countries. This paper reports the results of an experimental study on the mechanical properties of recycled aggregate concrete (RAC) as compared to natural aggregate concrete (NAC). The effects of size of RA on compressive strength were discussed in this paper. The $100 \%$ of RA used in concrete mix to replace the natural coarse aggregate in concrete with $100 \times 100 \times 100$ cube mm were cast with target compressive strength is $25 \mathrm{MPa}$. The 28 -day compressive strength was crushed at 3, 14, 28 days are reported. It was found the size of $10 \mathrm{~mm}$ and $14 \mathrm{~mm}$ of RA in RAC is quite similar performance with $10 \mathrm{~mm}$ and $14 \mathrm{~mm}$ size of natural aggregate (NA) in natural aggregate concrete (NAC).
\end{abstract}

Keywords: Concrete, Recycled aggregate properties, Performance of recycled aggregate concrete

\section{Introduction}

The applications of recycled aggregate in construction have started since end of World War II by demolished concrete pavement as recycled aggregate in stabilizing the base course for road construction (Olorusongo, F.T., 1999). The advantages of using recycle aggregate concrete in construction industry are of economic values and environmental issues. The wastes from construction and demolition works are of large volume and increasing in time. To overcome this issue, sustainable concrete construction is one of the strategies to be considered by the construction industry. One way of achieving these is to introduce recycled aggregates from these wastes of construction and demolition works into the production of concrete. As mentioned in the Ninth Malaysian Plan, the government encourage the use of recycled and reuse materials for construction industry. The reused of recycled aggregate (RA) is not common practice in the Malaysian construction industry nowadays because there is no depletion of natural aggregates (Diah And Majid, 1998). Time will comes where the sources of natural aggregate will soon decrease and Malaysia will encounter a reduction in its supply.

The use of recycled aggregate in replacing the normal coarse aggregates in concrete construction has become popular among researchers. They compare the performance and characteristics of the two aggregates used. Most researchers found that the performance of recycled aggregate used in concrete has low workability and compressive strength. The 
reasons for these are because of factors like smooth texture and rounder shape of RA, higher percentage of fine particles and high water absorption (Olorusongo, F.T., 1999).

Only one researcher found recycled aggregate concrete has higher compressive strength. He claimed that recycled aggregate has more angular shape and rough surface texture compare to natural aggregate. The angular shape and rough texture of RA leads to better bond and higher strength of concrete. To increase the compressive strength, RA should be oven dried condition that will create the interfacial bond between cement paste and aggregate particles (Poon, C. S., Shui, Z. H., Lam, L., Kou, S. C., 2004).

This study investigated the properties of RA according to BS 882:1992, and evaluated the compressive strength and workability of the concrete using recycled aggregate.

\section{Evaluation of Recycled Aggregate Properties}

Recycled aggregate can be generated from demolished construction structure which comprises of broken members or components likes the slab, beam, brick wall and others. Since the quality data of these broken materials are often unknown, such as water cement ratio, kind of admixtures, aggregate origins and gradations, as well as the differentiation of its properties during the performance time, thus it should refer to historical data of the components, physical characteristics, mechanical characteristics and environmental characteristics (Oikonomou, N. D., 2005).

The study of the properties of recycled aggregates and the basic properties of recycled concrete has been on going over the last few decades, leading a number of countries recommendations their use. The properties of RA are evaluated according to BS 812:1990, which require performing several tests that include (i) flakiness and elongation, (ii) water absorption and specific gravity, (iii) aggregate crushing value and aggregate impact value.

\subsection{The Properties}

The recycled aggregates are generated from demolished construction by crushing using steel hammer. It is then put into jaw crusher where it is broken down into required sizes. The crushed materials are sieved using a vibrator sieve in order to obtain aggregate with the sizes of $10 \mathrm{~mm}, 14 \mathrm{~mm}$ and $20 \mathrm{~mm}$. The aggregate properties are analyzed according to BS $882: 1992$.

\subsubsection{Flakiness Index and Elongation}

Flakiness Index is defined as the mass of flaky particles expressed as a percentage of the mass of the sample. Elongation index is defined as the percentages by weight of particles present in it with largest dimension (length). The flakiness and elongation tests are useful for general assessment of aggregates but they do not adequately describe the particle shape. To determine the indexes of the aggregate, it is sieved using vibrator sieve. The particles that retained are weighted and the index is determined by means of simple gauges described in BS 812: Section 105.2:1990(Neville, A. M., 2002).

Flakiness index thin and flat particles can reduce strength when load is applied to the flat side of the aggregate or across its shortest dimension and are also prone to segregation and breakdown during compaction, creating additional fines. If the aggregate has higher flakiness index and used for making concrete, the developed fresh concrete will have lower workability. Meanwhile, the elongated particles also adversely affect the strength of concrete especially the durability and flexural strength because the bond between the aggregate and cement paste depends on it (Gambhir, M. L., 2004).

The flakiness and elongation indexes tests on recycled and natural aggregates were conducted according to BS 812: Section 105.2:1990. The results are as shown in Table 5. The values of flakiness and elongation indexes of recycled aggregate are relatively lower than that of natural aggregate. Thus, the RA is flakier than NA and this will reduce the workability of concrete that use the RA. The overall results of RA flakiness index are lower than $40 \%$ limit (BS 882:1992), which means the RA is suitable to be used as coarse aggregate. RA is less elongated than NA and exceed $10 \%$ limit (threshold value) for desirable application as coarse aggregate (Neville, A. M., 2002).

\subsubsection{Water Absorption and Specific Gravity}

Water absorption is defined as the absorption rates of water by aggregate. It is determined by measuring the increase in mass of an oven dried sample when immersed in water for 24 hours. The ratio of the increase in mass to the sample, expressed as a percentage, is termed of absorption (Neville, A. M., 2002). The standard procedure is prescribed in BS 812: Part 105.2:1990. The absorption rate not only affects the bond between the aggregate and cement paste but also the specific gravity of the aggregate. When the water absorption of the aggregate is higher, it will decrease the workability of fresh concretes.

Past researchers had proved that the absorption rates of recycled aggregate are higher compared to natural aggregate (Olorusongo, F.T., 1999)(Diah And Majid, 1998)(Poon, C. S., Shui, Z. H., Lam, L., Kou, S. C., 2004)(Vivian, W. Y. T., Tam, C. M., 2006). The absorption rate gives the effect to the mix proportions in control water content and to maintain water-cement ratio constant. That means, in concrete design, the higher absorption gives the problems for workability and water demand. The result from this study as in table 5 shows the water absorption of RA increased according to 
the size of RA. It seen clearly, that RA with $10 \mathrm{~mm}$ size absorbed less water compared to other sizes of RA. The overall water absorption percentage for the three sizes of RA is below 5\%, this shows that RA can be used in any construction application. This is complying with BS 882:1992, which states a $10 \%$ maximum value of water absorption for coarse aggregate. Aggregate with water absorption this value can use for the application in structural element, non structural element and insulation barrier.

The specific gravity of an aggregate is defined as the ratio of the mass of solid in a given volume of sample to the mass an equal volume of water at the same temperature. The specific gravity is cluster under three different conditions namely bulk, apparent and saturated specific gravity. The bulk specific gravity is where the specific gravity of the aggregate is determined under the natural environment. The apparent specific gravity is determined after the aggregate is oven dried for 24 hours. The saturated specific gravity is determined when the aggregate is under the saturated condition. The specific gravity of an aggregate gives valuable information on its quality and properties and it is seen that the higher the specific gravity of an aggregate, the harder and strong it will be (Gambhir, M. L., 2004). The results of RA analysis on the specific gravity are as in table 5. The results show that the specific gravity values of RA are almost equal of the NA. This indicates that the qualities of RA are almost the same of the NA and can be used in any concrete mix.

\subsubsection{Aggregate Crushing Value and Aggregate Impact Value (ACV and AIV)}

According to BS 812: PART 112:1990 standard, the aggregate impact value is related to the crushing value. The tests to determine the values are prescribed in the standard.

In aggregate crushing value test, the aggregate is subjected to $400 \mathrm{KN}$ compression load in a cylindrical mold. The crushing value is defined by the percentage loss in mass on $2.36 \mathrm{~mm}$ size of test. Bigger percentage of aggregate crushing value means the aggregate is inferior in quality. According to BS 882:1992, aggregate with crushing value less than $25 \%$ can be used in heavy duty floor, crushing value for more than $30 \%$, aggregate to be used in concrete for wearing surfaces and for more than $45 \%$ it can be used other concrete purposes. The experimental result shows the crushing values of natural aggregate is $16.33 \%$ and recycled aggregate is $28.57 \%$ this means that natural aggregate is better than recycled aggregate as expected but the difference is not very significant. Since the value for recycled aggregate is slightly higher than $25 \%$, this shows it can be used for wearing surfaces concrete such as concrete slab and apron in construction.

For aggregate impact value test, the sample of the aggregate is placed in a cylindrical container where a standard hammer falling 15 times under its own weight. The impact value is determined as a percentage passing on $2.36 \mathrm{~mm}$ size sieve. The high value percentage denotes a low performance of aggregate in concrete or the strength of concretes in the field. In this study, as in table 5, shows that the impact values of recycled aggregate are similar compared to natural aggregate. This means that recycled aggregate can perform in the field quite similar strength in concrete when compared to natural aggregate.

\section{Performance of RA Concrete}

In this study, the recycled aggregate was used in making Recycled Aggregate Concrete (RAC). The concrete was molded into cubes of the size $100 \mathrm{~mm} \times 100 \mathrm{~mm} \times 100 \mathrm{~mm}$. The mixing of the concrete was done according to the DOE method for the targeted compressive strength of $25 \mathrm{MPa}$ at 28 days. Table 2- 4 gives the detailed of mix proportions. Three mixes were cast using the RA and NA with different sizes of $10 \mathrm{~mm}, 14 \mathrm{~mm}$ and $20 \mathrm{~mm}$. The $100 \%$ of recycled aggregate was used in the mix as a coarse aggregate for the recycled aggregate concrete. Based on mix design by DOE method, the target slump in this studied is between $60-180 \mathrm{~mm}$.

\subsection{Workability of RAC and NAC}

Workability of concrete defined as physical properties of concrete alone without referring to the circumstances of a particular type of construction. Workability is a property of fresh concrete and this is measured by slump test and describes as a measure consistency (Neville, A. M., 2002).

In figure 5, is clearly seen the slump obtained by RAC between $120-150 \mathrm{~mm}$ and for NAC, it shows the slump values is higher than RAC between 150-170 mm. The main factors affecting the workability of RAC are the higher rate of water absorption. This condition will affect the workability of the concrete mix that the RA is applied to.

RA exhibits water absorption higher than $15 \%$ is not acceptable in many countries (Vivian, W. Y. T., Tam, C. M., 2006). However, according to BS882, 1992, a maximum of $10 \%$ water absorption is accepted for many construction applications such as structural element, minor structural element and non-structural element. The preliminary result shows in table 5, the values of water absorption increases by the size of RA, meanwhile the NA proves to perform better in this aspect. The increasing replacement of RA in concrete, the workability of the concrete will decrease proportionally and lower workability of RAC is due to the mortar coating of RA, which led to higher water absorption (Topcu, I. B., 1997). Meanwhile, the internal pores and absorption in the aggregate particles was mentioned in 
connection with the specific gravity of aggregate and indeed the characteristics of these pores are very important in the study of its properties (Neville, A. M., 2002). Beside water, the texture and angular shape of RA are also recognized as a factor for lower workability of RAC (Ridzual et. Al., 2001). The identified that irregularity of RA surface contributed to lower workability of RAC (Batayaneh, M., Marie, I., Asi, I, 2006).

But in this study, the preliminary results show the rates of water absorption by RA are acceptable and not over than standard based on BS 882:1992.

\section{2 compressive strength}

Compressive strength for hardened concrete was determined by using compression machine. Figure 6-8 shows the results for compressive strength at 3,14 and 28 days. Strength of concrete is commonly considered its most valuable property in the mechanical properties because the strength usually gives an overall picture of the quality of concrete that is directly related to the structure of the hydrated cement paste.

Based on figure 6-8, gives the values of compressive strength for RAC and NAC according to the aggregate sizes and days of testing. The difference in compressive strength of two types of aggregate is clearly seen when comparing the 28-day compressive strength. It can be seen the RAC is lower workability and compressive strength compared to NAC. The RAC crushed at 3 days produced the similar strength by the all size of RA. At the age of 14 days, the RAC was quite similar value when compared to NAC in size $10 \mathrm{~mm}$ and $14 \mathrm{~mm}$, but in $20 \mathrm{~mm}$ size of RAC, this effect was different; the RAC was $10 \%$ weaker than NAC. At the age of 28 days, the results of RAC which is well within the same range of compressive strength value for NAC except in $20 \mathrm{~mm}$ sizes.

The several past researchers have conducted study for determining compressive strength of RAC compared to NAC. The factors such as smoother texture, rounder shape of RA, and higher percentage of fine particles were the reasons RA had lower compressive strength than NA (Olorusongo, F.T., 1999). Meanwhile, the more angular shape of RA and its rougher surface texture are what contribute to a higher compressive strength in recycled aggregate concrete (Ridzual et. al., 2001). An angular shape and rough texture in RA leads to better bonds and a higher strength value of concrete. RAC can also have a higher compressive strength when RA is oven dried, due to the interfacial bond between cement paste and aggregate particles (Poon, C. S., Shui, Z. H., Lam, L., Kou, S. C., 2004).

Overall the mixes was achieved the $25 \mathrm{MPa}$ target of compressive strength at 28-day ages. The recycled aggregate concrete is rapidly gains strength with their age.

\section{Conclusion}

From the experimental results, it can be concluded that:

1) The 28-day target compressive strength for all six mixes was achieved to $25 \mathrm{MPa}$ even though the RAC strength is lower than NAC. The compressive strength for RAC is within the same range compared to NAC and reaching up to $25 \mathrm{MPa}$ at day 28 of curing.

2) The size of RA was affected the strength in compressive strength, the results shows the $10 \mathrm{~mm}$ and $14 \mathrm{~mm}$ size of RA is better than $20 \mathrm{~mm}$ size.

3) The workability (slump test) of RAC is lower than NAC because the rate absorption of RA is higher than NA.

4) The general properties of RA including AIV, ACV and specific gravity show hardly any noticeable difference from NA, and thus it is proven that RA size affected the workability and strength of concrete and can be seen especially in water absorption.

5) Gives a manual guideline for Malaysian constructions industry to reuse a recycled aggregate in the future.

\section{References}

Batayaneh, M., Marie, I., Asi, I. (2006). Use of Selected Waste Materials in Concrete Mixes". Waste Management, available online at www.sciencedirect.com.

BS882, (1992). "specification for aggregate from natural sources for concrete".

Diah And Majid. (1998). "Penggunaan Sisa Kiub Sebagai Aggregat” at Jurutera, pp 45-50.

Gambhir, M. L. (2004). Concrete Technology Third Edition, Tata McGraw Hill Companies.BS

Neville, A. M. (2002). Properties of Concrete, Pearson Prentice Hall.

Oikonomou, N. D., (2005). "Recycled Concrete Aggregates". Cement and Concrete Composites, Vol 27, pp 315-318.

Olorusongo, F.T. (1999). "Early Age Properties of Recycled Aggregate Concrete". Proceeding of the International Seminar on Exploiting Wastes in Concrete held at the University of Dundee, Scotland, UK on 7 September 1999, pp 163-170.

Poon, C. S., Shui, Z. H., Lam, L., Kou, S. C. (January 2004). "Influence of Moisture States of Natural and Recycled Aggregates On The Slump and Compressive Strength of Concrete". Cement and Concrete Research, Vol 34, pp 31-36. 
Rancangan Malaysia Ke-9, pp. 472-473.

Ridzual et. al. (2001). ".Early Compressive Strength and Drying Shrinkage of Recycled Aggregate Concrete”. Proceedings of Seventh International Conference On Concrete Engineering and Technology, Selangor, Malaysia, June 5-7, 2001:51- 58 .

Topcu, I. B. (1997). "Physical and Mechanical Properties of Concretes Produced With Waste Concrete”. Cement and Concrete Research, vol 27, pp 1817-1823.

Vivian, W. Y. T., Tam, C. M. (February 2006). "Crushed Aggregate Production From Centralized Combined and Individual Waste Sources In Hong Kong”. Construction and Building Materials, Vol 21, pp 879-886.

www.utusan.com.my/utusan/SpecialCoverage/RMK9/html/bahasa.htm

Table 1. Standards for aggregate testing

\begin{tabular}{|c|c|}
\hline Testing & International standard \\
\hline $\begin{array}{c}\text { Flakiness \& } \\
\text { elongation }\end{array}$ & BS 812:PART 105.2:1990 \\
\hline $\begin{array}{c}\text { Water absorption \& } \\
\text { specific gravity }\end{array}$ & BS 812:PART 105.2:1990 \\
\hline $\begin{array}{c}\text { Aggregate crushing } \\
\text { value }\end{array}$ & BS 812:PART 112:1990 \\
\hline $\begin{array}{c}\text { Aggregate impact } \\
\text { value }\end{array}$ & BS 110:1990 \\
\hline
\end{tabular}

Table 2. Concrete mix proportion for $10 \mathrm{~mm}$ size aggregate $\left(\mathrm{kg} / \mathrm{m}^{3}\right)$

\begin{tabular}{|c|c|c|}
\hline No & Subject & Quantity \\
\hline 1 & Cement & 500 \\
\hline 2 & Fine aggregate (sand) & 794 \\
\hline 3 & Coarse aggregate & 260 \\
\hline 4 & Water & $60-180 \mathrm{~mm}$ \\
\hline 5 & Target slump & 2400 \\
\hline 6 & Density & \\
\hline
\end{tabular}

Table 3. Concrete mix proportion for $14 \mathrm{~mm}$ size aggregate $\left(\mathrm{kg} / \mathrm{m}^{3}\right)$

\begin{tabular}{|c|c|c|}
\hline No & Subject & Quantity \\
\hline 1 & Cement & 480 \\
\hline 2 & Fine aggregate (sand) & 810.5 \\
\hline 3 & Coarse aggregate & 843.4 \\
\hline 4 & Water & 240 \\
\hline 5 & Target slump & $60-180 \mathrm{~mm}$ \\
\hline 6 & Density & 2400 \\
\hline
\end{tabular}


Table 4. Concrete mix proportion for $20 \mathrm{~mm}$ size aggregate $\left(\mathrm{kg} / \mathrm{m}^{3}\right)$

\begin{tabular}{|c|c|c|}
\hline No & Subject & Quantity \\
\hline 1 & Cement & 450 \\
\hline 2 & Fine aggregate (sand) & 835.5 \\
\hline 3 & Coarse aggregate & 869.5 \\
\hline 4 & Water & 225 \\
\hline 5 & Target slump & $60-180 \mathrm{~mm}$ \\
\hline 6 & Density & 2400 \\
\hline
\end{tabular}

Table 5. Physical and mechanical Properties of RA compared to NA.

\begin{tabular}{|c|c|c|c|c|}
\hline Test & \multicolumn{3}{|c|}{ RA } & \multirow[t]{2}{*}{ NA } \\
\hline & $10 \mathrm{~mm}$ & $14 \mathrm{~mm}$ & $20 \mathrm{~mm}$ & \\
\hline Bulk Specific gravity & \multicolumn{3}{|c|}{2.36} & 2.41 \\
\hline Specific gravity (SSD) & \multicolumn{3}{|c|}{2.40} & 2.45 \\
\hline Specific gravity (apparent) & \multicolumn{3}{|c|}{2.51} & 2.51 \\
\hline Water absorption (\%) & 1.39 & 1.78 & 3.48 & 1.67 \\
\hline Aggregate impact value (\%) & \multicolumn{3}{|c|}{31.70} & 31.70 \\
\hline Aggregate crushing value (\%) & \multicolumn{3}{|c|}{28.57} & 16.33 \\
\hline Flakiness index (\%) & \multicolumn{3}{|c|}{19.40} & 38.35 \\
\hline Elongation index (\%) & \multicolumn{3}{|c|}{11.30} & 39.12 \\
\hline
\end{tabular}
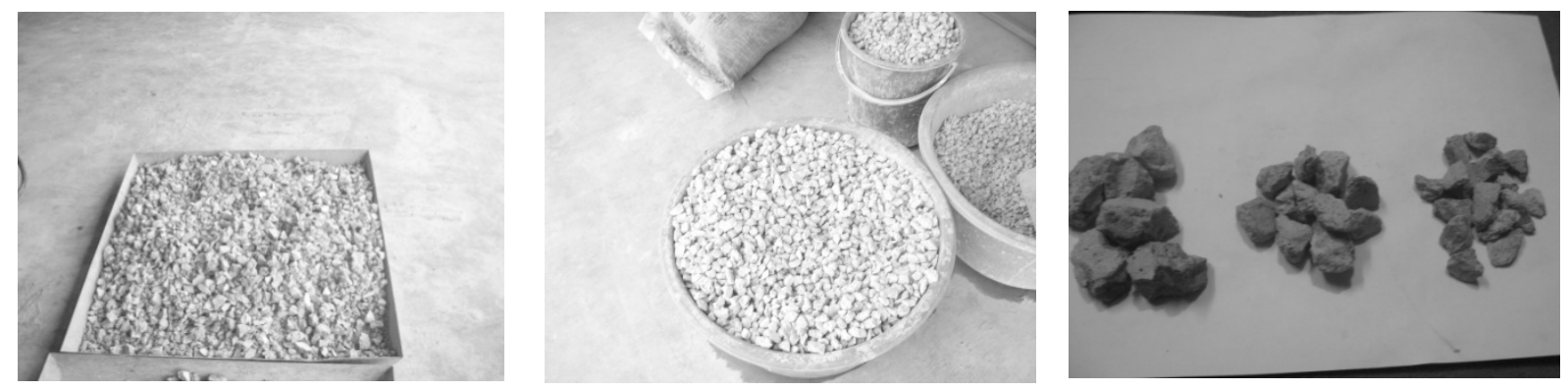

Figure 1. Recycled aggregate before and after sieve. 

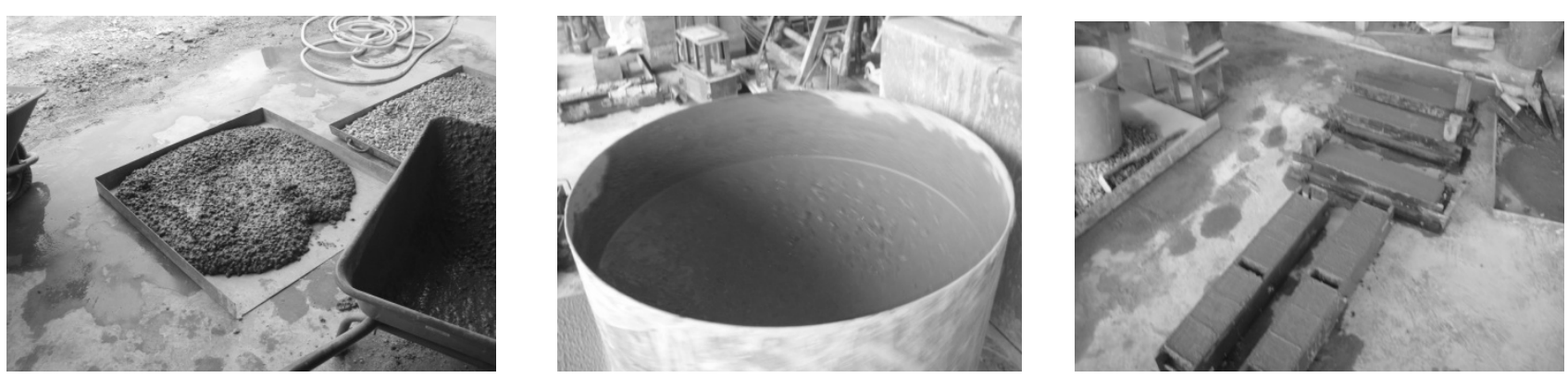

Figure 2. Mix and casting process.
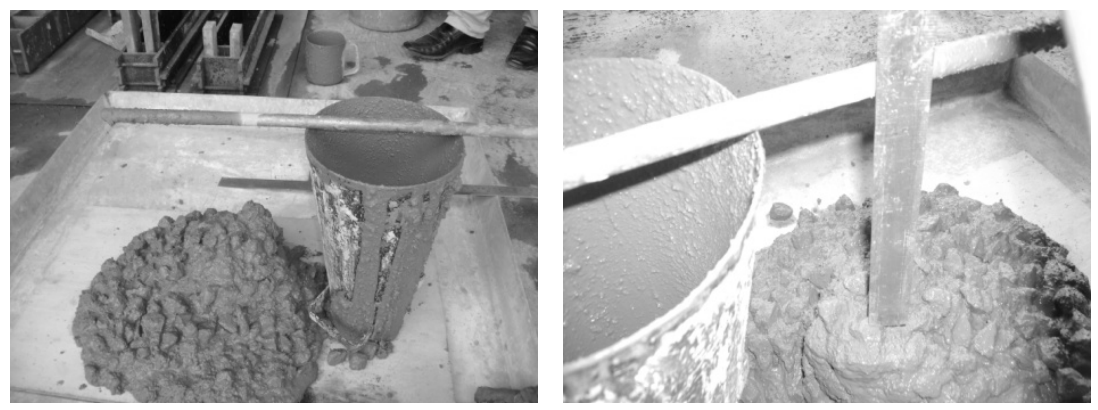

Figure 3. Slump test
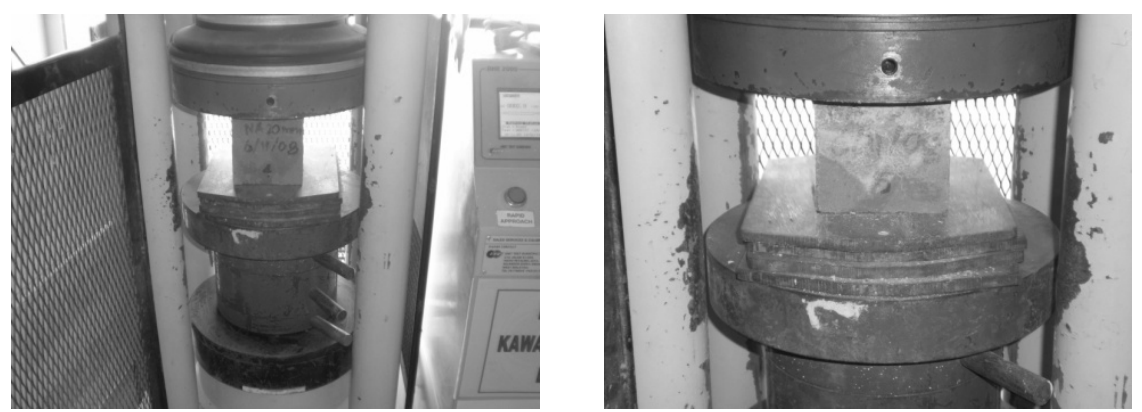

Figure 4. Compression test

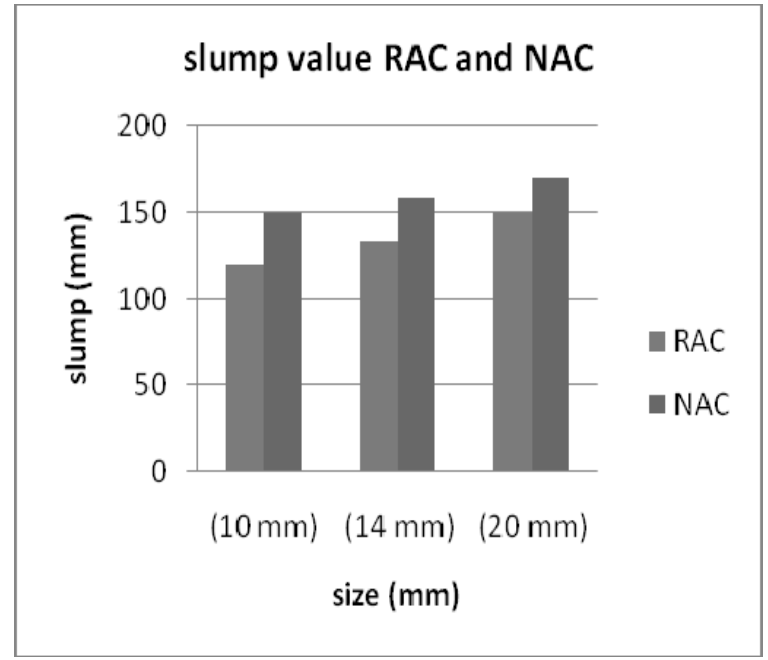

Figure 5. Slump value RAC and NAC 


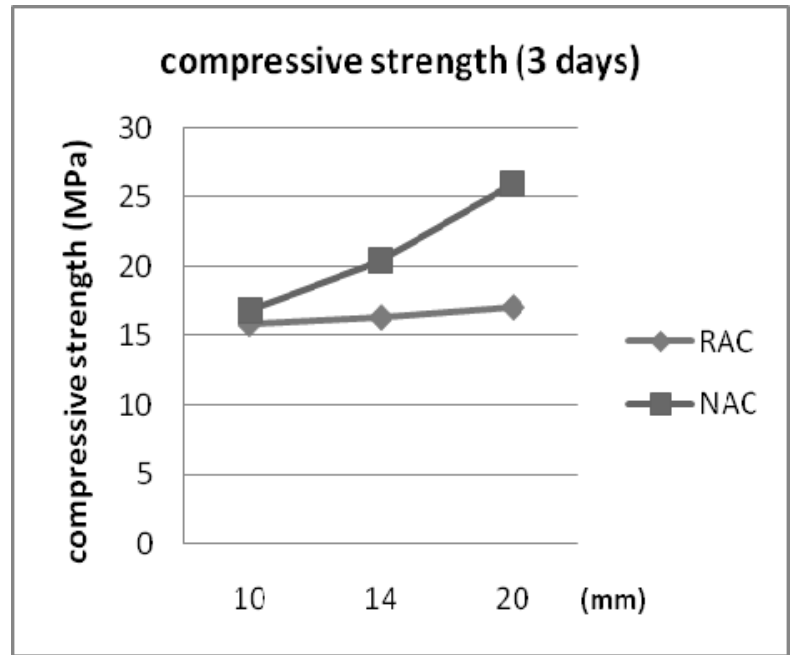

Figure 6. Compressive strength (3 days)

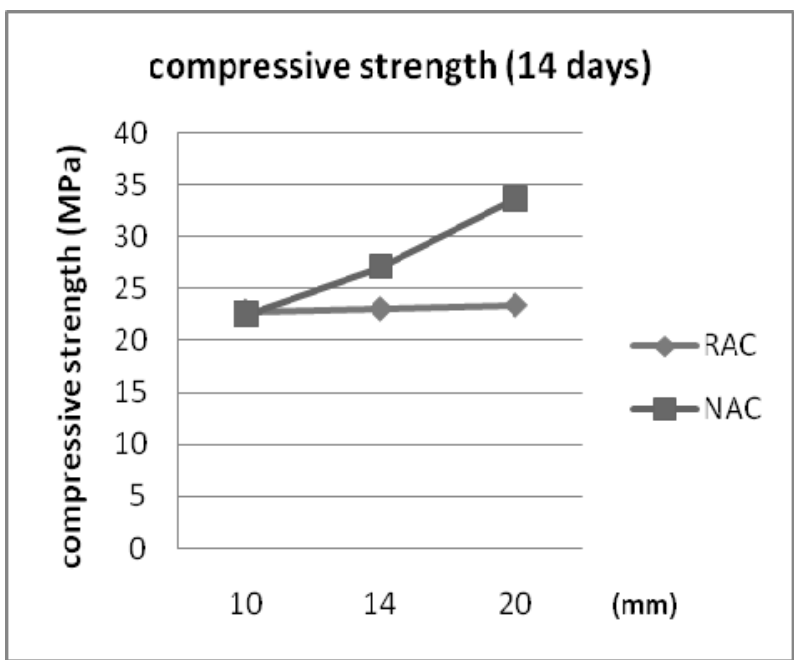

Figure 7. Compressive strength (14 days)

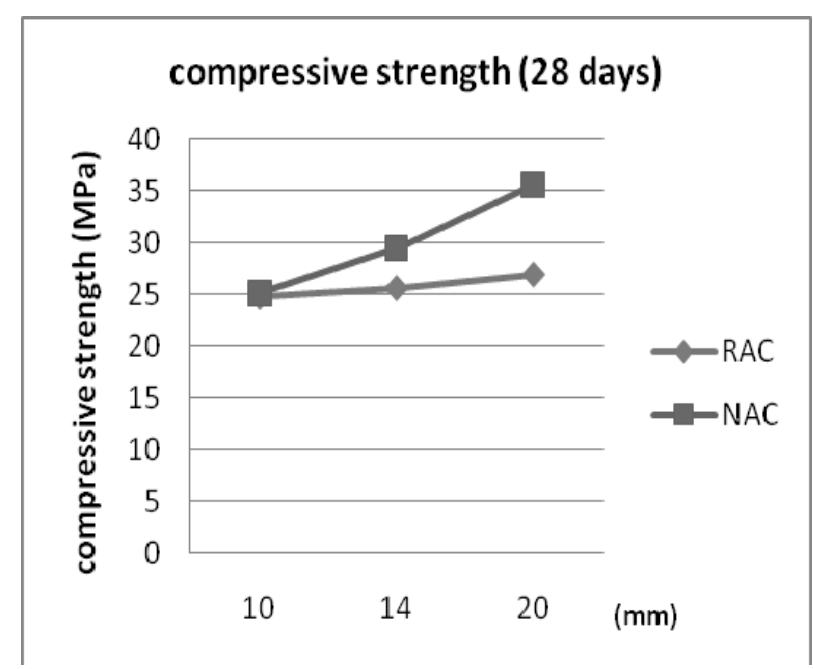

Figure 8. Compressive strength (28 days) 